\title{
Níveis de fósforo disponível em rações para suínos de alto potencial genético para deposição de carne dos 30 aos $60 \mathrm{~kg}^{1}$
}

\section{Alysson Saraiva ${ }^{2}$, Juarez Lopes Donzele ${ }^{3}$, Rita Flávia Miranda de Oliveira ${ }^{3}$, Márvio Lobão Teixeira de $\mathrm{Abreu}^{4}$, Francisco Carlos de Oliveira Silva ${ }^{5}$, Douglas Haese ${ }^{2}$}

\author{
${ }^{1}$ Financiado pelo CNPq. \\ 2 Programa de Pós-graduação em Zootecnia - UFV. \\ ${ }^{3} D Z O-U F V$. \\ ${ }^{4} D Z O$ - UFPI. \\ ${ }^{5}$ EPAMIG.
}

RESUMO - Com o objetivo de avaliar níveis de fósforo disponível (Pd) em rações para suínos de alto potencial para deposição de carne, foram utilizadas 60 fêmeas suínas, híbridas comerciais, com peso inicial de 30,0 \pm 0,618 kg, distribuídas em delineamento inteiramente casualizado, com cinco tratamentos, seis repetições e dois animais por unidade experimental. Os tratamentos foram constituídos de uma ração basal sem suplementação de fósforo e outras quatro rações, obtidas pela suplementação da ração basal com fosfato bicálcico de forma a se obterem cinco níveis de Pd $(0,115 ; 0,195 ; 0,275 ; 0,355$ e 0,435\%). Não foi observado efeito dos níveis de Pd sobre o consumo de ração. Os níveis de fósforo disponível influenciaram de forma linear o ganho de peso diário (GPD) e a conversão alimentar (CA), de modo que o GPD aumentou até o nível de 0,349\% de Pd, permanecendo em um platô. A conversão alimentar diminuiu até 0,345\% de Pd, no qual permaneceu em um platô. A resistência óssea, os teores de fósforo nos ossos e a porcentagem de cinzas nos ossos foram influenciados de forma linear crescente pelos níveis de Pd das rações. Não houve efeito dos níveis de Pd das rações sobre a quantidade de cálcio nos ossos. Os níveis de Pd que proporcionam os melhores resultados de ganho de peso e conversão alimentar de fêmeas suínas de alto potencial genético para deposição de carne dos 30 aos $60 \mathrm{~kg}$ são, respectivamente, 0,349 e 0,345\%, que correspondem a consumos diários estimados de 7,45 e 7,36 g.

Palavras-chave: exigência, genótipo, minerais, nutrição, suínos

\section{Available phosphorus levels in diets for swine with high genetic potential for meat deposition from 30 to $60 \mathrm{~kg}$}

\begin{abstract}
With the objective of evaluating levels of available phosphorus (AP) in diets for swine with high genetic potential for meat deposition, sixty female commercial hybrid swine were used, with initial weight of $30 \pm 0.618 \mathrm{~kg}$, distributed in a completely randomized experimental design, with five treatments, six replications and two animals per experimental unit. The treatments consisted of a basal diet without phosphorus supplementation and another four diets obtained by supplementing the basal diet with dicalcium phosphate to obtain five available phosphorus levels $(0.115,0.195$ $0.275,0.355$ and $0.435 \%$ ). No effect of the available phosphorus levels was observed on the feed daily intake. The available phosphorus levels influenced linearly the daily weight gain (DWG) and the feed conversion (FC), and the daily weight gain increased up to the level of $0.349 \%$ available phosphorus, and remained on a plateau. The feed conversion decreased to $0.345 \%$ of available phosphorous and remained on a plateau. The bone strength, phosphorus levels and ash percentage in the bones linearly increased as available phosphorous levels increased in the rations. There was no effect of the available phosphorous levels of the diets on the amount of calcium in the bones. The available phosphorous levels that showed the best results for daily weight gain and feed conversion in female swine with high genetic potential for meat deposition, from 30 to $60 \mathrm{~kg}$, are, respectively, 0.349 e $0.345 \%$, corresponding to the estimated daily intakes of 7.45 and $7.36 \mathrm{~g}$.
\end{abstract}

Key Words: genotype, minerals, nutrition, requirement, swine

\section{Introdução}

A busca por maior produtividade do setor suinícola, assim com a demanda crescente do consumidor por carne com menor teor de gordura e de melhor qualidade, têm levado à seleção e à produção de suínos com maior potencial genético para crescimento, eficiência alimentar e melhor composição de carcaça. Entretanto, a introdução 
desses genótipos no mercado requer maior atenção dos nutricionistas, pois, de acordo com Hendricks et al. (1993), suínos com diferentes potenciais genéticos para deposição de tecido magro apresentam diferenças em suas exigências de minerais.

Dos minerais suplementados em rações para suínos o fósforo tem exigido atenção especial, pois, além de desempenhar grande número de funções no organismo, a deposição de tecido muscular exige energia na forma de ATP. Quantitativamente a mais importante função do fósforo é a formação e mineralização da matriz orgânica do osso. No entanto, o fósforo ainda atua como componente dos ácidos nucleicos (DNA e RNA), que são essenciais para o crescimento e a diferenciação celular e, juntamente com outros elementos, participam na manutenção da pressão osmótica e do equilíbrio ácido-básico. Como um componente dos fosfolipídeos, contribui para fluidez e integridade da membrana celular.

Além de anormalidades ósseas, a deficiência de fósforo pode causar baixa ingestão de ração, redução na eficiência alimentar, distúrbios reprodutivos e alterações do apetite (Underwood \& Sutlle, 1999).

Estudos para determinação das exigências de cálcio e fósforo de suínos têm sido realizados com base no ganho de peso, na conversão alimentar, no consumo de ração, na resistência do osso à quebra e nos teores de cálcio, fósforo e cinzas nos ossos. A exigência de cálcio e fósforo dietéticos para aumento do crescimento e da eficiência alimentar é inferior à exigência para aumento da resistência óssea (Combs et al., 1990).

Assim, no estabelecimento de programas de alimentação visando máxima expressão do potencial genético produtivo dos suínos, em qualquer fase do ciclo de criação, é necessário que as exigências nutricionais sejam determinadas para atender às necessidades dos animais. É necessário considerar ainda a poluição ambiental causada pelos dejetos de suínos e o desenvolvimento de novos materiais genéticos lançados no mercado, que possuem maior potencial para deposição muscular. Assim, são necessárias constantes redefinições das exigências de fósforo disponível dessas novas linhagens para não comprometer o desempenho dos animais e/ou contribuir para o aumento na excreção desse mineral para o meio ambiente.

Este trabalho foi realizado com o objetivo de avaliar os efeitos de níveis de fósforo disponível em rações para suínos de alto potencial genético para deposição de carne na fase dos 30 aos $60 \mathrm{~kg}$.

\section{Material e Métodos}

O experimento foi conduzido no Setor de Suinocultura do Departamento de Zootecnia da Universidade Federal de Viçosa (UFV), em Viçosa, Minas Gerais.

Foram utilizadas 60 fêmeas suínas híbridas comerciais, com peso inicial de 30,00 \pm 0,618 kg, distribuídas em delineamento inteiramente casualizado, com cinco tratamentos (níveis de fósforo disponível), seis repetições e dois animais por unidade experimental, representada pela baia.

Os animais foram alojados em baias com piso de concreto, dotadas de comedouros semiautomáticos e bebedouros automáticos tipo chupeta, localizadas em galpão de alvenaria. A temperatura no interior do galpão foi aferida diariamente, uma vez ao dia ( $8 \mathrm{~h}$ ), por meio de termômetro de máxima e mínima, durante todo o período experimental.

As rações experimentais (Tabela 1) foram formuladas à base de milho e farelo de soja e suplementadas com minerais e vitaminas para atenderem às exigências dos animais, de acordo com Rostagno et al. (2005), exceto em fósforo disponível. Os tratamentos consistiram de uma ração basal e de outras cinco rações, obtidas pela suplementação da ração basal com fosfato bicálcico em substituição à areia lavada, resultando em rações com 0,115; 0,195; 0,275; 0,355; e 0,435\% de fósforo disponível.

As rações e a água foram fornecidas à vontade aos animais. As rações, as sobras e os desperdícios foram pesados semanalmente e os animais, pesados no início e no final do período experimental, que durou 30 dias, para determinação do consumo de ração e de fósforo disponível, do ganho de peso e da conversão alimentar.

No final do período experimental, após jejum de 12 horas, um animal de cada unidade experimental com peso mais próximo dos $60,0 \mathrm{~kg}$ foi abatido por sangramento para coleta da pata anterior direita. As patas coletadas foram colocadas em recipiente de alumínio contendo água e fervidas, por 25 minutos, visando ao amolecimento da pele e da carne que envolve os ossos para retirada do terceiro osso metacarpiano. O metacarpo de cada animal abatido foi mantido em estufa ventilada a $65^{\circ} \mathrm{C}$ durante 72 horas e, então, submetido à quebra por flexão, indicadora da resistência óssea, utilizando-se o aparelho Instron Corporation IX Automated Materials Testing System - modelo 4204, pertencente ao Laboratório de Papel e Celulose do Departamento de Engenharia Florestal da Universidade Federal de Viçosa, segundo Teixeira et al. (2005). 
Tabela 1 - Composição das rações experimentais

\begin{tabular}{|c|c|c|c|c|c|}
\hline \multirow[t]{2}{*}{ Ingrediente } & \multicolumn{5}{|c|}{ Nível de fósforo disponível (\%) } \\
\hline & 0,115 & 0,195 & 0,275 & 0,355 & 0,435 \\
\hline Milho & 55,698 & 55,698 & 55,698 & 55,698 & 55,698 \\
\hline Farelo de soja & 39,485 & 39,485 & 39,485 & 39,485 & 39,485 \\
\hline Óleo soja & 1,483 & 1,483 & 1,483 & 1,483 & 1,483 \\
\hline Fosfato bicálcico & 0,000 & 0,433 & 0,983 & 1,298 & 1,730 \\
\hline Calcário & 1,534 & 1,258 & 0,865 & 0,706 & 0,430 \\
\hline Areia lavada & 0,900 & 0,743 & 0,586 & 0,430 & 0,274 \\
\hline DL-metionina & 0,025 & 0,025 & 0,025 & 0,025 & 0,025 \\
\hline Mistura vitamínica ${ }^{1}$ & 0,200 & 0,200 & 0,200 & 0,200 & 0,200 \\
\hline Mistura mineral ${ }^{2}$ & 0,200 & 0,200 & 0,200 & 0,200 & 0,200 \\
\hline Promotor de crescimento 3 & 0,050 & 0,050 & 0,050 & 0,050 & 0,050 \\
\hline Sal & 0,415 & 0,415 & 0,415 & 0,415 & 0,415 \\
\hline Butil-hidroxi-tolueno & 0,010 & 0,010 & 0,010 & 0,010 & 0,010 \\
\hline Total & 100,00 & 100,00 & 100,00 & 100,00 & 100,00 \\
\hline \multicolumn{6}{|l|}{ Composição nutricional calculada } \\
\hline Energia metabolizável (kgcal/kg) & 3.230 & 3.230 & 3.230 & 3.230 & 3.230 \\
\hline Proteína bruta $(\%)^{4}$ & 22,510 & 22,510 & 22,510 & 22,510 & 22,510 \\
\hline Lisina digestível (\%) ${ }^{4}$ & 1,104 & 1,104 & 1,104 & 1,104 & 1,104 \\
\hline Metionina + cistina digestível $(\%)^{4}$ & 0,660 & 0,660 & 0,660 & 0,660 & 0,660 \\
\hline Sódio (\%) & 0,180 & 0,180 & 0,180 & 0,180 & 0,180 \\
\hline Cálcio (\%) & 0,700 & 0,700 & 0,700 & 0,700 & 0,700 \\
\hline Cálcio analisado (\%) & 0,730 & 0,730 & 0,730 & 0,730 & 0,730 \\
\hline $\mathrm{P}$ total analisado(\%) & 0,343 & 0,423 & 0,503 & 0,583 & 0,663 \\
\hline $\mathrm{P}$ disponível $(\%)^{5}$ & 0,127 & 0,207 & 0,287 & 0,367 & 0,447 \\
\hline Relação cálcio:fósforo analisada & 2,13 & 1,72 & 1,45 & 1,25 & 1,10 \\
\hline
\end{tabular}

Depois de quebrados, os ossos foram desengordurados em extrator Soxhlet e levados novamente a estufa ventilada a $105^{\circ} \mathrm{C}$ durante 24 horas e, em seguida, foram triturados em moinho de bola.

A determinação dos teores de cálcio e fósforo das rações experimentais, bem como das concentrações de cálcio, fósforo e cinzas nos ossos, foi realizada no Laboratório da Rodes Química Cajati LTDA, em Cajati, São Paulo, segundo metodologia descrita por Silva \& Queiroz (2002). As análises estatísticas foram realizadas utilizando-se os procedimentos para análise de variância e de regressão, contidos no Sistema para Análises Estatísticas e Genéticas (SAEG), desenvolvido na Universidade Federal de Viçosa (UFV, 2000), versão 8.0.

As características de desempenho e dos parâmetros ósseos foram interpretadas por meio de análise de variância a 5\% de probabilidade. As estimativas dos níveis de fósforo disponível foram determinadas por meio de modelos de regressão linear, quadrático ou descontínuo Linear Response Plateau (LRP), descritos por Braga (1983), conforme o melhor ajustamento dos dados para cada variável e com base no fenômeno em estudo.

\section{Resultados e Discussão}

Durante o período experimental, a temperatura mínima e a máxima no interior do galpão mantiveram-se, respectivamente, em $19,8 \pm 1,6^{\circ} \mathrm{C}$ e $24,6 \pm 2,0^{\circ} \mathrm{C}$. Considerando que a faixa ideal de temperatura para suínos na fase de crescimento sugerida por Coffey et al. (2000) está entre 16 e $24^{\circ} \mathrm{C}$, constatou-se, com base na variação da temperatura ocorrida na condução do experimento, que os animais não foram submetidos a estresse térmico, o que possibilitou a expressão de seu máximo potencial genético para produção.

Não houve efeito $(\mathrm{P}>0,05)$ dos níveis de Pd sobre o consumo diário de ração dos animais (Tabela 2). Esses resultados estão coerentes com os obtidos por O’Quinn et al. (1997) e Hastad et al. (2004), que, trabalhando com suínos na fase de crescimento, também não observaram efeito significativo dos níveis de Pd da ração sobre o consumo de ração.

Por outro lado, Eeckhout et al. (1995), avaliando níveis de 0,11 a $0,17 \%$ de Pd para suínos em crescimento, observaram efeito linear crescente dos níveis de Pd sobre 
Tabela 2 - Valores de desempenho e parâmetros ósseos de suínos recebendo diferentes níveis de fósforo disponível na ração dos 30 aos $60 \mathrm{~kg}$

\begin{tabular}{|c|c|c|c|c|c|c|}
\hline \multirow[t]{2}{*}{ Variável } & \multicolumn{5}{|c|}{ Nível de fósforo disponível (\%) } & \multirow[t]{2}{*}{$\mathrm{CV} \%$} \\
\hline & 0,127 & 0,207 & 0,287 & 0,367 & 0,447 & \\
\hline Peso médio final (kg) & 54,93 & 57,53 & 58,53 & 61,07 & 60,45 & - \\
\hline Consumo de ração (g/dia) & 2.063 & 2.148 & 2.123 & 2.191 & 2.146 & 6,67 \\
\hline Consumo de PD (g/dia) ${ }^{1}$ & 2,62 & 4,45 & 5,17 & 8,04 & 8,15 & 7,36 \\
\hline Ganho de peso (g/dia) ${ }^{1}$ & 834 & 920 & 957 & 1027 & 1013 & 8,17 \\
\hline Conversão alimentar 1 & 2,47 & 2,33 & 2,22 & 2,13 & 2,12 & 6,17 \\
\hline Resistência óssea $(\mathrm{N})^{1}$ & 659,05 & 742,14 & 774,28 & 877,30 & 949,68 & 19,08 \\
\hline Fósforo no osso $(\mathrm{g} / \mathrm{kg})^{1}$ & 85,12 & 86,54 & 91,34 & 93,17 & 91,30 & 3,57 \\
\hline Cálcio no osso (g/kg) & 189,33 & 184,80 & 196,80 & 204,00 & 195,40 & 6,37 \\
\hline Teor cinza óssea $(\%)^{1}$ & 48,34 & 49,81 & 52,21 & 54,42 & 52,20 & 4,37 \\
\hline
\end{tabular}

${ }^{1}$ Efeito linear $(\mathrm{P}<0,01)$.

o consumo voluntário de ração. Outros autores, como Ketaren et al. (1992) e Ekpe (2002), em pesquisa com suínos em crescimento recebendo diferentes níveis de Pd, constataram que o consumo de ração variou de forma quadrática, aumentando até os níveis estimados de 0,30 e 0,35\% de Pd, respectivamente.

Considerando os resultados de consumo de ração verificados neste estudo, pode-se inferir que baixos níveis de fósforo na ração de suínos na fase de 30 a 60 kg não comprometem o consumo voluntário de alimento pelos animais. Essa observação não está de acordo com os resultados de Reinhart \& Mahan (1986), que, em pesquisa com suínos na fase de crescimento, verificaram que rações com baixos níveis de fósforo ( 0,38 e $0,47 \%$ fósforo total) diminuíram o consumo de ração pelos animais.

O ganho de peso diário (GPD) aumentou $(\mathrm{P}<0,01)$ de forma linear conforme aumentaram os níveis de fósforo disponível das rações. No entanto, o modelo Linear Response Plateau (LRP) foi o que melhor se ajustou aos dados, estimando em 0,349\% o nível de Pd a partir do qual o GPD permaneceu em um platô (Figura 1). Resultado semelhante foi obtido por Eeckhout et al. (1995), que, em suínos dos 37 aos $61 \mathrm{~kg}$, também observaram efeito linear crescente dos níveis de Pd (0,11 a 0,17\%) sobre o GPD dos animais.

Apesar do padrão de resposta similar do GPD ao aumento dos níveis de Pd verificado entre os trabalhos, o nível de Pd $(0,349 \%)$ que proporcionou o melhor resultado de ganho de peso neste estudo foi $51,3 \%$ superior ao de $0,17 \%$ de Pd, o que permite inferir que, apesar da possível diferença entre a genética dos animais em potencial para crescimento em tecido magro, o nível de 0,17\% de Pd utilizado por Eeckhout et al. (1995) pode não ter sido suficiente para atender às exigências dos animais para máximo ganho de peso.

Estudos têm evidenciado que as exigências de minerais podem variar de acordo com o potencial genético dos

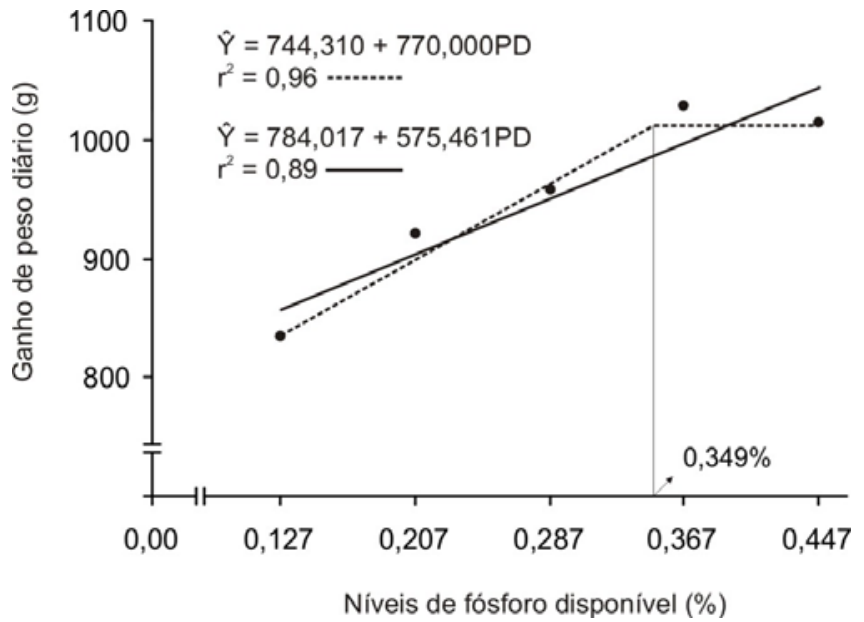

Figura 1 - Ganho de peso diário de fêmeas suínas dos 30 aos $60 \mathrm{~kg}$ alimentadas com rações com diversos níveis de fósforo disponível.

suínos para deposição de tecido magro (Hendricks et al., 1993; Mahan, 2006). Segundo Wiseman et al. (2007), suínos de alto potencial genético para deposição de carne apresentam maior conteúdo em tecido magro e ósseo que suínos de genética inferior, o que pode justificar sua maior exigência de fósforo disponível.

Respostas quadráticas do GPD de suínos em crescimento a níveis crescentes de fósforo disponível da ração foram encontradas por Stahly et al. (2000) e Ekpe et al. (2002), que verificaram aumento do GPD até os níveis estimados, respectivamente, de 0,40 e 0,35\% de Pd. Os resultados deste estudo diferem dos encontrados por O’Quinn et al. (1997) e Hastad et al. (2004), que trabalhando com suínos de alto potencial genético, respectivamente, dos 25 aos $55 \mathrm{~kg}$ e dos 33 aos $55 \mathrm{~kg}$, avaliaram diferentes níveis de Pd nas rações e não observaram efeito significativo sobre o ganho de peso.

Ressalta-se que as elevadas relações cálcio:fósforo total (Ca:P) de 2,13; 1,72 e 1,45 das dietas com níveis mais 
baixos de fósforo disponível (0,127; 0,207 e 0,287\%) promoveram os menores ganhos de peso diário dos animais. Alta relação Ca:P na dieta pode reduzir a absorção do fósforo, resultando em menores taxas de ganho de peso (NRC, 1998; Liu et al., 2000). Em pesquisa com suínos nas fases inicial, de crescimento e terminação, Reinhard \& Mahan (1986) verificaram que a taxa de ganho de peso e a eficiência alimentar dos animais consumindo rações com baixos níveis de fósforo foram influenciadas de forma negativa. O NRC (1998) preconiza que a relação Ca:P em dietas à base de milho e soja deve estar entre 1:1 e 1,25:1.

Os níveis de fósforo disponível influenciaram $(\mathrm{P}<0,01)$ a conversão alimentar (CA) dos animais, que melhorou de forma linear com o aumento dos níveis de fósforo disponível nas rações. No entanto, o modelo LRP foi o que melhor se ajustou aos dados, estimando em 0,345\% o nível de fósforo disponível a partir do qual a conversão alimentar permaneceu em um platô (Figura 2). De forma semelhante, Eeckhout et al. (1995) avaliaram rações com níveis de Pd entre 0,11 e $0,17 \%$ e observaram que a conversão alimentar de suínos na fase de crescimento variou de forma linear decrescente.

Em contrapartida, Stahly et al. (2000), em suínos dos 37 aos 65 kg alimentados com rações com diferentes níveis de fósforo, verificaram melhora quadrática na eficiência alimentar, que melhorou até o nível estimado de $0,40 \%$ de Pd. Esses resultados estão coerentes com os obtidos por Ekpe et al. (2002), que também verificaram melhora quadrática na eficiência alimentar de suínos dos 23 aos 60 kg com o aumento dos níveis de Pd das rações até o nível estimado de $0,350 \%$ Pd.

Uma vez que o consumo diário de ração não foi significativamente influenciado pelos níveis de fósforo disponível, a melhora na conversão alimentar neste estudo permite inferir que, além do aumento no ganho de peso até o nível de $0,349 \%$ de Pd, os níveis de fósforo disponível possivelmente alteraram a composição do ganho de peso dos animais. Assim, maior deposição de tecido muscular em relação à deposição de gordura pode ter ocorrido nos animais que consumiram níveis mais elevados de Pd. Essa hipótese se baseia nos resultados verificados por Cromwell et al. (1970) e Stahly (2007), que concluíram que níveis de fósforo abaixo da exigência em ração para suínos, além de diminuir o GPD e a eficiência alimentar, podem influenciar de forma negativa a relação entre a deposição de proteína e gordura na carcaça, pois aumentam o conteúdo de gordura corporal dos animais. De acordo com Krick et al. (1992), o aumento no ganho de peso dos suínos, associado à melhora na conversão alimentar, pode ser justificado principalmente pela maior deposição de tecido protéico.

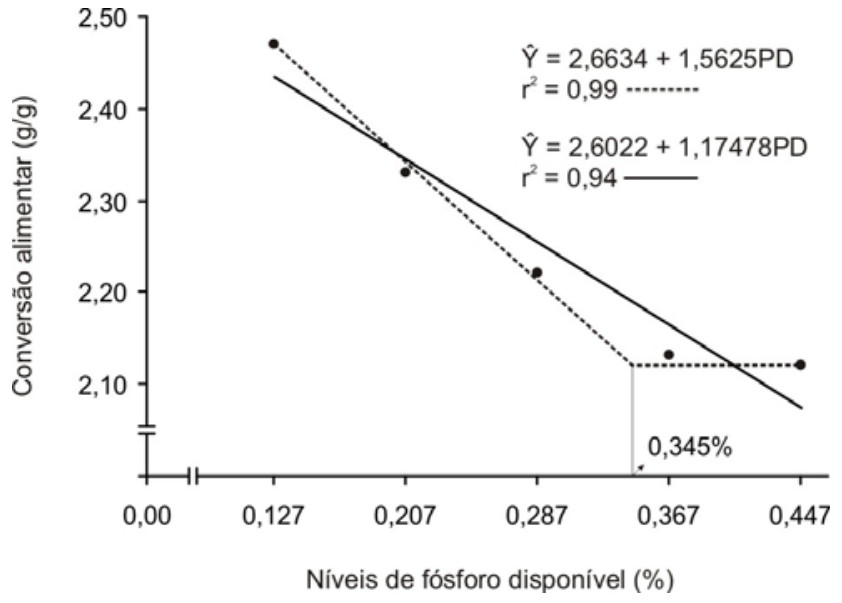

Figura 2 - Conversão alimentar de fêmeas suínas dos 30 aos 60 kg alimentadas com rações com diversos níveis de fósforo disponível.

O fósforo é um nutriente crítico para a síntese de proteína corporal e se destaca no metabolismo de energia (via ATP) como componente dos ácidos nucléicos e dos fosfofolipídeos da membrana celular. De acordo com Frederick \& Stahly (1998) e Stahly (2007), a concentração de fósforo no tecido muscular é significativamente alta em comparação à do tecido adiposo. Assim, os aumentos na exigência de Pd de suínos selecionados para maior deposição de tecido magro são consequência do aumento na demanda de fósforo necessário para síntese de proteína muscular.

O melhor resultado de conversão alimentar obtido com o nível de $0,345 \%$ de Pd neste estudo, correspondente a consumo diário de 7,36 g de fósforo disponível, evidencia que os níveis de 0,230 e de 0,332\% de Pd recomendados, respectivamente, pelo NRC (1998) e por Rostagno et al. (2005), podem não ser adequados para atender às exigências de suínos em crescimento dos atuais genótipos disponíveis no mercado.

Os níveis de fósforo disponível influenciaram $(\mathrm{P}<0,01)$ a resistência óssea, que aumentou de forma linear, segundo a equação: $\hat{\mathrm{Y}}=543,9510+893,3270 \mathrm{PD}\left(\mathrm{r}^{2}=0,99\right)$. Esse resultado corrobora aqueles obtidos por Ketaren et al. (1992) e Eeckhout et al. (1995), que também verificaram efeito linear crescente dos níveis de fósforo disponível sobre a resistência óssea do terceiro metacarpo de suínos em crescimento. Entretanto, esses autores verificaram efeito quadrático dos níveis de Pd sobre a resistência óssea dos animais quando a análise foi realizada no quarto metacarpo. De forma semelhante, O’Quinn et al. (1997) constataram efeito quadrático dos níveis de fósforo disponível sobre a resistência óssea de suínos dos 25 aos 50 kg. Por outro lado, Hastad et al. (2004), trabalhando com 
suínos dos 33 aos 55 kg, não observaram efeito significativo dos níveis de Pd sobre a resistência óssea do terceiro e quarto metatarsos.

Neste estudo o nível de Pd que proporcionou máximo ganho de peso dos animais foi estimado em 0,349\%, enquanto a resistência óssea aumentou de forma linear com o aumento dos níveis de Pd. Esses resultados corroboram os relatos de Crenshaw et al. (1986) e Combs et al. (1990) de que a exigência de fósforo para máximo ganho de peso e eficiência alimentar de suínos na fase de crescimento ocorre em níveis inferiores àqueles necessários para aumentar a resistência óssea.

A variação entre os trabalhos na estimativa de níveis de fósforo disponível da ração para suínos a partir da avaliação da resistência óssea provavelmente se deve aos tipos de ossos utilizados nos testes. Essa proposição está coerente com os resultados encontrados por Crenshaw et al. (1981), que avaliando a influência de diferentes níveis de fósforo sobre as propriedades mecânicas de vários ossos de suínos, concluíram que diferenças nas estimativas da exigência de fósforo dependem do tipo de osso utilizado. Segundo esses autores, fatores como comprimento do osso e sua orientação no equipamento, além do tipo de equipamento, também podem ser responsáveis por essas variações.

Considerando os resultados de resistência óssea verificados neste trabalho, houve redução de 30\% na resistência óssea dos animais que consumiram ração com menor nível de $\mathrm{Pd}(0,127 \%)$ em comparação aos animais que consumiram ração com maior nível de Pd (0,447\%). Em comparação à redução de $17 \%$ no GPD, observada nos animais que receberam os mesmos níveis de Pd, verificou-se que o maior prejuízo ocasionado pela ração com menor nível de Pd foi sobre a resistência óssea. Assim, animais selecionados geneticamente para deposição de tecido magro privilegiam o ganho de peso em detrimento da integridade óssea quando submetidos à deficiência de fósforo. Esse fato foi constatado por Hittmeier et al. (2006) em suínos de duas linhagens (pura e híbrida) na fase inicial de crescimento. Segundo esses autores, o maior grau de mineralização óssea nos suínos puros em comparação aos híbridos, ambos consumindo ração com nível deficiente de fósforo, é um indicativo de que os animais puros provavelmente sacrificam sua taxa de crescimento como forma de poupar fósforo para manutenção da integridade óssea, o que sugere diferença na intensidade do controle homeorrético da utilização do fósforo entre as duas genéticas.

Mudanças na expressão de determinados genes da medula óssea, observadas por Hittmeier et al. (2006) podem explicar essa alteração do metabolismo do fósforo. De acordo com esses autores, os níveis de transcrição do fator de crescimento semelhante a insulina ligado à proteína 3 (IGFLP3) e de receptores de calcitonina (RCALC) e de vitamina D (RVD) aumentaram na medula óssea dos suínos puros mas não se alteraram nos animais híbridos. O aumento na expressão do gene para RCALC nos animais puros pode indicar maior inibição da atividade dos osteoclastos, o que reduz a reabsorção óssea e contribui para a preservação de sua integridade. Nos suínos híbridos, a expressão genética de RCALC não foi responsiva à deficiência dietética de fósforo, permitindo a atividade normal dos osteoclastos e, consequentemente, a reabsorção óssea, disponibilizando fósforo para crescimento em tecido protéico.

Os tratamentos influenciaram $(\mathrm{P}<0,01)$ os níveis de fósforo nos ossos (PO), que aumentaram de forma linear de acordo com os níveis de Pd das rações, segundo a equação: $\hat{Y}=82,6430+23,5363 P D\left(r^{2}=0,77\right)$.

De forma diferente, Gomes et al. (1989a,b) não observaram diferença significativa dos níveis de fósforo disponível das rações sobre os teores de fósforo nos ossos de suínos dos 31 aos $62 \mathrm{~kg}$ e dos 62 aos $93 \mathrm{~kg}$.

Não se observou efeito $(\mathrm{P}>0,05)$ dos níveis de Pd sobre a quantidade de cálcio nos ossos (CaO). De forma semelhante, Huertas (1992), avaliando diferentes níveis de fósforo total com porcas em gestação, não observou diferença significativa nos teores de cálcio das vértebras caudais.

Com base nos relatos de Mahan et al. (1980) de que a mineralização óssea não aumenta de forma linear com o aumento dos níveis de fósforo da ração, é possível inferir, pelos resultados de resistência óssea e fósforo nos osso obtidos neste trabalho, que o maior nível de Pd $(0,447 \%)$ não foi suficiente para promover máxima mineralização dos ossos.

A porcentagem de cinzas no osso dos animais foi influenciada $(\mathrm{P}<0,01)$ de forma linear crescente pelos níveis de Pd das rações, de acordo com a equação: $\hat{Y}=46,9299$ $+15,2174 \mathrm{PD}\left(\mathrm{r}^{2}=0,71\right)$. Esses resultados estão de acordo com aqueles obtidos por Eeckhout et al. (1995), que também relataram aumento linear do teor de cinzas do terceiro e quarto metacarpos de suínos em crescimento de acordo com os níveis de Pd da ração. Da mesma forma, Hastad et al. (2004) observaram efeito linear crescente do teor de cinzas ósseas do quarto metatarso de suínos dos 33 aos $55 \mathrm{~kg}$ com o aumento dos níveis de Pd. No entanto, quando se analisou o teor de cinzas ósseas do terceiro metatarso, não foi observado efeito significativo dos níveis de fósforo disponível.

Variações nos resultados de cinzas ósseas também foram observadas por Cromwell et al. (1970). Esses autores, 
avaliando o teor de cinzas ósseas no metacarpo e no osso da concha nasal de suínos, concluíram que a divergência de resultados foi ocasionada pelo tipo de osso utilizado e sugeriram que o osso da concha nasal é o mais adequado para ser utilizado na estimativa de exigência de Pd dos suínos por ser mais sensível à deficiência de fósforo em comparação a outros tipos ósseos.

\section{Conclusões}

Os níveis de fósforo disponível de 0,349 e 0,345\%, correspondentes a consumos diários estimados de 7,45 e 7,36 g, proporcionam, respectivamente, os melhores resultados de ganho de peso e conversão alimentar de fêmeas suínas de alto potencial genético para deposição de carne na fase dos 30 aos $60 \mathrm{~kg}$.

\section{Literatura Citada}

BRAGA, J.M. Avaliação da fertilidade do solo (ensaio de campo). Viçosa, MG: Imprensa Universitária, 1983. 101p.

COFFEY, R.D.; PARKER, G.R.; LAURENT, K.M. [2000]. Feeding growing-finishing pigs to maximize lean grow rate. Disponível em: <http://www.animalgenome.org/edu/PIH/prod_ grow_finish.pdf $>$. Acesso em: 14/05/2007.

COMBS, N.R.; KORNEGAY, E.T.; LINDEMANN, M.D. et al. Calcium and phosphorus requirement of swine from weaning to market weight: II. Development of response curves for bone criteria and comparison of bending and shear bone testing. Journal of Animal Science, v.69, p.682-693, 1990.

CRENSHAW, T.D.; PEO, E.R.; LEWIS, A.J. et al. Bone strength as a trait for assessing mineralization in swine: a critical review of techniques involved. Journal of Animal Science, v.53, p.827, 1981.

CRENSHAW, T.D. Reliability of dietary Ca and P levels and bone mineral content as a predictors of bone mechanical properties at various time periods in growing swine. Journal of Nutrition, v.116, p. 2155, 1986.

CROMWELL, G.L.; HAYS, V.W.; CHANEY, C.H. et al. Effects of dietary phosphorus and calcium levels on performance, bone mineralization and carcass characteristics of swine. Journal of Animal Science, v.30, p.519, 1970.

EECKHOUT, W.; PAEPE, M.; WARNANTS, N. et al. An estimation of the minimal $\mathrm{P}$ requirements for growing-finishing pigs, as influenced by the Ca level of the diet. Animal Feed Science and Technology, v.52, p.29-40, 1995.

EKPE, E.D.; ZIJLSTRA, R.T.; PATIENCE, J.F. Digestible phosphorus requirement of grower pigs. Canadian Journal of Animal Science, p.541-549, 2002.

GOMES, P.C.; ROSTAGNO, H.S.; PEREIRA, J.A.A. et al. Exigência de fósforo total e disponível para suínos na fase de crescimento. Revista da Sociedade Brasileira de Zootecnia, v.18, n.3, p.233-239, 1989a.

GOMES, P.C.; ROSTAGNO, H.S.; FONSECA, J.B. et al. Exigência de fósforo total e disponível para suínos na fase de terminação. Revista da Sociedade Brasileira de Zootecnia, v.18, n.3, p.241-247, 1989b.

GUEGUEN, L.; PEREZ, J.M. A re-avaluation of recommended dietary allowances of calcium and phosphorus for pigs. Proceedings of Nutrition Society, v.40, p.273, 1981.

HASTAD, C.W.; DRITZ, S.S.; TOKACH, M.D. et al. E. Phosphorus requirements of growing-finishing pigs reared in a commercila enviroment. Journal of Animal Science, v.82, p.2945-2952, 2004.

HENDRIKS, W.H.; MOUGHAN P.J. Whole-body mineral composition of entire male and female pigs depositing protein at maximal rates. Livestock Productions Science, v.33, p.161-170, 1993.

HITTMEIER, L.J.; GRAPES, L.; LENSING, R.L. et al. Genetic background influences metabolic response to dietary phosphorus restriction. Journal Nutrition Biochemistry, v.17, p.385-395, 2006.

HUERTAS, C.A.P. Exigências nutricionais de fósforo em porcas nas fases de gestação e lactação. 1992. 163f. Tese (Doutorado em Zootecnia) - Universidade Federal de Viçosa, Viçosa, MG, 1992.

KETAREN, P.P.; BATTERHAM, E.S.; WHITE, E. Phosphorus studies in pigs. 1. Available phosphorus requirements of grower/finisher pigs. British Journal of Nutrition, v.70, p.249-268, 1992.

KRICK, B.J.; BOYD, R.D. Influence of genotype and sex on the response of growing pigs to recombinant porcine somatotropin. Journal of Animal Science, v.70, p.3024, 1992.

LIU, J.; BOLLINGER, D.W.; LEDOUX, D.R. et al. Effects of dietary calcium:phosphorus ratios on apparent absorption of calcium and phosphorus in small intestine, cecum and colon of pigs. Journal of Animal Science, v.78, p.106-109, 2000.

MAHAN, D.C.; EKSTROM, K.E.; FETTER, A.W. Effect of dietary protein, calcium and phosphorus for swine from 7 to 20 kilograms body weight. Journal of Animal Science, v.50, n.2, p.309-314, 1980.

MAHAN, D.C. [2006]. Necessidades de minerales em cerdos selecionados por um alto contenido em magro y cerdas de alta productividad. Disponível em: <http://www.etsia.upm.es/ fedna/capitulos/06CAP_VIII.pdf $>$. Acesso em: 18/5/2007.

NATIONAL RESEARCH COUNCIL - NRC. Nutrient requirements of swine. 9.ed. Washington, D.C.: National Academy of Science, 1998. 189p.

O'QUINN, P.R.; KNABE, D.A.; GREGG, E.J. Digestible phosphorus needs of terminal-cross growing-finishing pigs. Journal of Animal Science, v.75, p.1308-1318, 1997.

REINHARD, G.A.; MAHAN, D.C. Effect of various calcium: phosphorus ratios at low and high dietary phosphorus for starter, grower and finishing swine. Journal of Animal Science, v.63, p.457-466, 1986.

ROSTAGNO, H.S.; ALBINO, L.F.T.; DONZELE, J.L. et al. Tabelas brasileiras para aves e suínos: composição de alimentos e exigências nutricionais. 2.ed. Viçosa, MG: Imprensa Universitária, 2005. 186p.

SILVA, D.J.; QUEIROZ, A.C. Análise de alimentos (métodos químicos e biológicos). 3.ed. Viçosa, MG: Universidade Federal de Viçosa, 2002. 235p.

STAHLY, T.S.; LUTZ, T.R.; CLAYTON, R.D. [2000]. Dietary available phosphorus needs of high lean pigs fed from 9 to $119 \mathrm{~kg}$ body weight. ASR-L655. Disponível em: <http://www.ipic.iastate.edu/ reports/00swinereports/asl-655.pdf>. Acesso em: 20/6/2007.

STAHLY, T.S. Nutrient needs for high lean pigs. Manitoba agriculture, food and rural initiatives. Disponível em: <http://www.gov.mb.ca/agriculture/livestock/pork/swine/ bab10s13.html>. Acesso em: 1/6/2007.

TEIXEIRA, A.O.; LOPES, D.C; GOMES, P.C. et al. Níveis de substituição de fosfato bicálcico pelo monobicálcico em dietas para suínos em crescimento e terminação. Revista Brasileira de Zootecnia v.34, n.2, p.142-150, 2005.

WISEMAN, T.G.; MAHAN, D.C.; PETERS, J.C. et al. Tissue weights and body composition of two genetics lines of barrows and gilts from twenty to one hundred twenty-five kilograms of body weight. Journal of Animal Science, v.85, p.1825-1835, 2007.

UNDERWOOD, E.J.; SUTTLE, N.F. The mineral nutrition of livestock. 3.ed. New York: CABI Publishing, 1999. 598p.

UNIVERSIDADE FEDERAL DE VIÇOSA - UFV. Sistemas de análises Estatísticas e Genéticas - SAEG. Viçosa, MG: 2000. (Versão 8.0). 